\title{
Usos e lugares da fotografia nos museus de arte
}

Guilherme Tosetto

Faculdade de Belas-Artes da Universidade de Lisboa - Portugal

\begin{abstract}
Resumo
O objetivo deste artigo é identificar e compreender o momento em que a fotografia passa de instrumento utilitário a serviço da arte para se tornar obra de arte, quando assume valor de culto e, consequentemente, desperta o interesse museológico. O período histórico da virada nos usos da fotografia é marcado pela sua relaçáo com a emergente arte conceitual dos anos 1960 e 1970 e pela crescente crítica e teoria, que deram origem a textos e autores ainda citados em pesquisas sobre fotografia. Recentemente, com a entrada dos museus e coleçóes no ambiente digital, sua função utilitária torna-se cada vez mais complexa, e o seu lugar como obra de arte, cada vez mais diluído na contemporaneidade.
\end{abstract}

Palavras-chave: Fotografia; Museus; Arte.

\begin{abstract}
The purpose of this article is to identify and evaluate the moment when photography turns into a work of art, departing from being a mere utilitarian instrument to the service of art, assuming cult value and, consequently, arousing museological interest. The historical period of this turning point in the uses of photography is marked by its relations with an emerging conceptual art at 60's and 70's, and also by its criticism and theory, that gave rise to texts and authors still cited in photography's researches. Recently, when museums and collections have entered the digital environment, its utilitarian function have become increasingly essential, and its place as work of art increasingly diluted in contemporaneity.
\end{abstract}

Keywords: Photography; Museums; Art. 
1 Há também uma discussão acerca desta data, tanto que foram celebrados dois centenários da fotografia, um em 1925, em referência ao invento de Niépce em 1825 , e uma segunda comemoração em 1939 referente a fotografia apresentada por Daguerre em 1839. Ver CHALLINE, Eléonore. Photography and Memory. Étude photographique, n.25, 2010.

2 BAUDELAIRE, Charles. Le public moderne et la photographie. Etudes photographiques, 1999.
Se hoje a fotografia tem seu lugar de destaque nos museus de arte, sobretudo enquanto obra e objeto de coleção, podemos dizer que, antes desse lugar razoavelmente estável, foi preciso a sua aceitação como uma forma possível de expressão artística, o que não ocorreu de maneira tão simples. Até as primeiras décadas do século XX, ela ainda buscava sua autonomia e sua linguagem própria, enquanto servia como instrumento de documentação e reprodução no campo das artes.

O primeiro passo na direção da valoração da fotografia como obra de arte foi dado pelo MoMA, em 1941, quando Alfred Barr, o primeiro diretor do museu de Nova Iorque, criou o departamento de fotografia, tendo como chefe de área o historiador da arte Beaumont Newhall. Este departamento se ocuparia desta nova mídia, equiparada então com outras que despontavam na época, como o cinema e o design. Em 1947, o fotógrafo Edward Steichen foi nomeado diretor do departamento de fotografia do museu norte-americano. Contudo, a apreciação estética e a aquisição de fotografia como obra de arte em outros importantes museus da época foi bastante tímido. Algumas instituiçôes só iniciaram de fato suas coleçôes fotográficas no final da década de 1970 .

Pode-se afirmar que as complexas relações entre fotografia e arte advêm de sua gênese, quando na França, a Academia de Ciência, meses após anunciar a invenção da fotografia, realizou uma sessão conjunta com a Academia de Belas Artes em agosto de $1839^{1}$, para explicar o então revolucionário processo fotográfico.

Desde aquele momento a fotografia oscilou como uma aliada e uma ameaça para as artes tradicionais. Um dos pontos altos desta querela foi expresso no histórico texto $O$ público moderno e a fotografia, escrito por Baudelaire sobre o Salão da Academia de Belas Artes de 1859, exatos 20 anos após a 'descoberta' ${ }^{1}$ da fotografia: "Nestes dias deploráveis, produziu-se uma nova indústria que muito contribuirá para confirmar a idiotice da fé que nela se tem, e para arruinar o que poderia restar de divino no espírito francês." 'Ao escrever estas palavras sobre a 'nova indústria' da fotografia, na carta endereçada ao editor da Revue Française, o autor procurou rebater com certa ironia toda a euforia que era depositada na imagem técnica nascente. Para o autor, este novo meio saciaria a obsessão dos artistas pelo registro pictórico do 'real', até então proporcionado apenas pela pintura, e, por fim, a fotografia seria a grande responsável pelo declínio do gosto francês expresso nas artes. Porém, sem menosprezar os avanços que a fotografia traria naquele momento histórico, Baudelaire procura colocá-la no seu devido lugar, não de protagonismo, nem de substituição da 'arte', mas de instrumento com o dever de servi-la por meio de sua inegável verossimilhança, 
Se for permitido à fotografia substituir a arte em qualquer uma de suas funçôes, ela logo será totalmente suplantada e corrompida, graças à aliança natural que encontrará na tolice da multidão. É preciso então que ela retorne ao seu verdadeiro dever, que é o de ser a serva das ciências e das artes, a mais humilde das servas. ${ }^{3}$

Daquele período incipiente da fotografia até a virada do século, quando a técnica e os aparelhos tornaram-se mais acessíveis, muitos artistas passam a utilizá-la, e outros tantos fotógrafos trabalham no sentido de aproximá-la do campo artístico. Neste contexto o movimento pictorialista assumiu importância, pois além de ser uma resposta a massificação da fotografia, foi significativo para o reconhecimento do seu potencial artístico.

Através do uso de artifícios próprios da técnica fotográfica, os pictorialistas criavam uma imagem menos preocupada em ser um 'registro do real' e mais interessada em explorar uma linguagem própria do meio, o que a aproximava dos propósitos criativos e subjetivos da arte. Para Phillipe Dubois, ${ }^{4}$ o pictorialismo era o desejo de a fotografia se fazer pintura, ao mesmo tempo que explicitava uma impossibilidade prática e teórica de tal empreendimento, devido às suas próprias contradiçôes.

Ainda segundo o autor, o movimento tornou-se a encruzilhada onde acontece a 'inversão' da fotografia, que vivia em uma relação de aspiração à arte, e que "ao longo do século XX será a arte que insistirá em se impregnar de certas lógicas próprias à fotografia." 5

Justamente no início do século $\mathrm{XX}$, ao se aproximar do movimento modernista, a fotografia dá um novo passo, quando procura redefinir suas raízes estéticas e se afasta da tradição pictórica. Ao se alinhar com o discurso de rompimento com as formas tradicionais de arte, assume um novo papel como instrumento para os ideais de experimentação e liberdade pregados pelo modernismo. E, ao assumir uma certa autonomia enquanto objeto, continua atuante, porém, de maneira mais autêntica no campo artístico da época.

Se a fotografia produz visibilidades modernas, é porque a iluminação que ela dissemina sobre as coisas e sobre o mundo entra em ressonância com alguns dos grandes princípios modernos; é por ajudar a redefinir, em uma direção moderna, as condiçôes do ver. ${ }^{6}$

Mesmo ao se tornar um meio expressivo da modernidade e sendo adotada por artistas em suas práticas, a fotografia ainda não havia conquistado seu lugar no mercado da arte e nos museus. Tanto que, quando as institui-
3 Ibidem.

4 Cf. DUBOIS, Philippe. $O$ ato fotográfico e outros ensaios, 1993.

5 Ibidem, p. 253.

6 ROUILLÉ, André. A fotografia entre documento e arte contemporânea, 2009, p. 39. 
7 BADGER, Gerry. Collecting

Photography, 2003, p. 9.

8 CRIMP, Douglas. Sobre as ruinas do museu, 2005, p. 3.

9 A exposição comissariada por Sérgio Mah e Paul Wombell, fez parte da programação da Photoespańa 2009 e reuniu 23 artistas.

10 CRIMP, Douglas. Sobre as ruinas do museu, 2005, p. 86. çôes colecionadoras se abrem para a fotografia entre o final dos anos 1970 e início dos 1980, uma das primeiras ações é justamente a recuperação das vanguardas históricas da fotografia, cujos autores e obras se localizam na esteira do modernismo.

Gerry Badger, em Collecting Photography, localiza o ápice da aproximação da fotografia com as artes no surgimento da arte conceitual na década de 1970, quando artistas passam a utilizar a câmera fotográfica como ferramenta de registro, potencializando seu uso clássico dentro de um universo criativo e, consequentemente, influenciando a mudança do olhar dos museus para a fotografia. Nesse sentido, muitos dos próprios artistas tornaram-se fotógrafos. Disto resultavam fotografias sem grandes pretensóes estéticas, mas que se transformavam em obra de arte pois eram as únicas frações visuais retiradas do desenvolvimento das obras.

\footnotetext{
A década de 1970 também viu o início do controverso movimento da arte conceitual, que, com ênfase no conceito e não na manufatura, seu interesse em formas de arte populares e sua crescente conscientizaçáo sobre a importância cultural da câmera, levou muitos artistas a fazer fotografias. ${ }^{7}$
}

Para Douglas Crimp, dois acontecimentos foram relevantes para a transformação dos usos da fotografia nesta década: o materialismo histórico na fotografia e as práticas fotográficas dissidentes. ${ }^{8}$

O primeiro acontecimento está relacionado com as mudanças que a fotografia impôs na sociedade, quando as melhorias técnicas, como a popularização de câmeras portáteis e a comercialização de filmes coloridos, ampliaram a prática fotográfica e passaram a fazer parte do cotidiano das pessoas. Conforme afirmou Sergio Mah por ocasião da exposição Años 70 Fotografía y vida cotidiana, "a década de 70 é um espelho da cultura contemporânea, quando observar a banalidade é base das narrativas." Já as práticas fotográficas dissidentes são justamente aquelas localizadas na arte conceitual, que utiliza a imagem técnica como registro e meio para divulgação de obras transitórias e efêmeras, ou ainda fazem uso da fotografia para além do registro referencial, aproximando-a do hibridismo com outras técnicas artísticas.

Crimp acredita tanto na virada da fotografia neste período que chega a afirmar que "a fotografia pode ter sido inventada em 1839, mas só foi descoberta na década de 1970."10

É evidente que quando a fotografia é entendida como obra de arte e entra nas coleçóes museológicas, ela instaura uma fissura e passa a exigir uma atenção especial que antes era voltada exclusivamente para os meios 
tradicionais, como a pintura. Douglas Crimp, porém, acredita que se por um lado a fotografia poderia estar no epicentro de uma convulsão museológica, seu aparecimento aliviava outros tipos de crises sentidas naquela época:

A recessão econômica da metade dos anos 70 reduziu os orçamentos operacional e de aquisiçóes dos museus, e era possível adquirir, expor e emprestar fotografias a um custo muito menor que o necessário para os objetos tradicionais do museu. Mas a crise não era meramente econômica; dos anos 60 em diante, as manifestaçôes da arte contemporânea esgotaram os recursos dos museus, não financeiramente, mas física e ideologicamente. ${ }^{11}$

O caráter heterogêneo da fotografia consegue trazer um ar de novidade ao museu, sem, contudo, despender, pelo menos inicialmente, grandes cifras para iniciar suas coleçôes fotográficas. Ao surgir como um novo meio, ela também chacoalhou as estruturas sedimentadas das instituiçóes e do colecionismo em geral, pois se viram obrigados a se aproximar do caráter estético da fotografia, que até então só tinha sua dimensão técnica valorizada neste universo.

Neste sentido, Jacques Derrida afirma que esta abordagem da fotografia no contexto das coleções acaba por fazer parte de um ciclo da história, quando um meio surge para substituir outro, gerando, assim, um novo valor de culto que direciona uma mais-valia sempre que aparece como novidade.

\footnotetext{
Há colecionadores que coletam fotografias exatamente como há aqueles que coletam documentos originais, não fotográficos ou pré-fotográficos. Quando a fotografia se torna uma arte, há uma mais-valia do arquivo que está conectado ao neo-arcaísmo de uma arte que é considerada tecnicamente superada ou que se tornou secundária; e de repente, a fotografia torna-se assim "cultivada" - no sentido da cultura e do culto religioso - como o livro foi antes do cinema e da televisão, como escrever à mão antes da impressão, antes da máquina de escrever ou do computador, etc. ${ }^{12}$
}

É certo que a fotografia em si não era uma novidade técnica nos anos 1970, mas ela passou a ser vista como um meio essencial no contexto artístico incipiente. Sérgio Mah, credita essa 'apoteose' da fotografia dentro do domínio da arte ao surgimento de análises e críticas no campo teórico ${ }^{13}$ ao longo dos anos 70 e início dos 80 , que procuraram dar conta destas mudanças socioculturais advindas desta mídia:

não deixa de ser interessante notar que o momento da apoteose da fotografia no campo da arte seja coincidente com o momen-
11 Ibidem, p. 86.

12 DERRIDA, Jacques. Mal de arquivo: uma impressäo freudiana, 2001, p. 52.

13 Para citar alguns exemplos clássicos: Sobre Fotografia de Susan Sontag, 1977; Notas Sobre o Índice de Rosalind Krauss, 1977; A Câmera Clara de Roland Barthes, 1981; Filosofia da Caixa Preta de Vilém Flusser, 1983 e O Ato Fotográfico de Philippe Dubois, 1984. 
$14 \mathrm{MAH}$, Sérgio. A fotografia na era da sua obsolescência, 2012, p. 29.

15 COSTA, Helouise. Da fotografia como arte a arte como fotografia: a experiência do Museu de Arte Contemporânea da USP na década de 1970, 2008, p.132.

16 Ibidem, p.133.

17 Cf. FONTCUBERTA, Joan. A câmera de Pandora: a fotografia depois da fotografia, 2012. to em que de algum modo se eclipsa a própria noção de medium (específico e coeso), e que a fotografia, muito para além das retóricas tecnicistas e das pretensóes de uma arte - singular, autônoma, exclusiva - ressurge como um objecto teórico, cada vez mais propenso a absorver e a imiscuir-se em todas as áreas da vida social e da arte. ${ }^{14}$

Os debates em torno da fotografia antes deste período se restringiam somente a questóes técnicas e seus usos enquanto instrumento em diversas áreas do conhecimento, como nas ciências exatas. Importante lembrar também que até este período, no âmbito da arte, a discussão se reduzia em torno do questionamento se a fotografia poderia ser considerada arte ou náo. Sendo assim, só com o amadurecimento no campo teórico estas questôes poderiam ser superadas, e fotografia e arte passaram a partilhar problemáticas relacionadas à estética e à sua significação.

Helouíse Costa também corrobora a opiniáo ao localizar nos anos 70 o importante papel da crítica da fotografia pensada justamente a partir de sua institucionalização:

Foi somente a partir dos anos 1970, com o advento da chamada crítica pós-moderna, que o interesse pelos processos de institucionalização da arte ganhou fôlego no trabalho de autores como Rosalind Krauss, Douglas Crimp e Abigail Salomon-Goudeau, para citar apenas alguns dos nomes, cuja produção teórica refere-se mais diretamente à fotografia. Não por acaso, parte desses autores valeu-se das questóes suscitadas pela assimilação da fotografia pelo museu para fundamentar suas reflexôes acerca da institucionalização da arte moderna e contemporânea e evidenciar seus paradoxos. ${ }^{15}$

Para a autora, historicamente, a legitimação da fotografia pelos museus de arte passa necessariamente por três estratégias: a primeira é a institucionalização da fotografia, quando o museu passa a "valorizar a fotografia não enquanto imagem reprodutivel e versátil, mas enquanto objeto de coleçâo", pautado assim por valores já aplicados a outras manifestaçóes artísticas. ${ }^{16} \mathrm{~A}$ segunda via se deu "por meio da pop arte, da arte conceitual e das diferentes práticas artísticas de caráter experimental desenvolvidas ao longo das décadas de 1960 e 1970", conforme já apontado por outros autores. E a terceira, localizada nos anos 1980, quando "os grandes museus de arte passaram a valorizar fotografias que seguem um certo modelo pictórico" vigente, como impressôes em grandes formatos e imagens coloridas.

Joan Fontcuberta ${ }^{17}$ identifica esta mudança no ciclo da fotografia, ou seja, sua incorporação ao mercado da arte e a entrada no museu como obra, 
também a partir dos anos 1960, porém sob outra abordagem. Para ele, este processo de institucionalização foi devido a um conjunto de fatores que começa pelo 'estabelecimento de padrôes historiográficos acadêmicos' na fotografia. Estes padrôes possibilitaram distinguir, nas imagens técnicas produzidas até aquele momento, a noção de autoria, estilo, escola, obra, etc., permitindo, deste modo, uma nova leitura da história da fotografia, agora com categorias mais próximas das utilizadas na história da arte.

Outro episódio destacado por Fontcuberta na transformação da fotografia e sua incorporação pelas instituições museológicas aconteceu no ano de 1989, quando houve 'faustosas' comemoraçôes dos 150 anos da fotografia - em relação a imagem produzida em 1839 por Daguerre - em alguns museus de arte do mundo, com exposiçóes dedicadas integralmente à fotografia produzida até aquele período. ${ }^{18} \mathrm{Em}$ suma, além do espírito de celebração, estas exposiçóes estavam impregnadas por um sentido retrospectivo e enaltecedor das qualidades da fotografia, que, passados 150 anos de transformaçóes, estavam aptas para entrar pela porta da frente dos museus de arte e ali permanecerem.

Ainda segundo Fontcuberta, este enaltecimento carregou consigo uma série de valores relativos à fotografia, que a credenciavam como mercadoria e peça de coleção:

o fetichismo de assinatura, a noção de original, de edição ilimitada, das qualidades técnicas inerentes a singularidade da tiragem fotográfica, de mise en valeur com a apresentação apropriada; em outras palavras: a recuperação da aura. ${ }^{19}$

Assim, o fato de dotar a fotografia de padróes historiográficos e de valores que antes eram exclusivos das artes 'tradicionais', somado à valorização da fotografia na década de 1980, com as importantes exposições retrospectivas organizadas por grandes museus, resultou na possibilidade de "discriminar frente a uma enorme produção de imagens fotográficas quais eram as peças desprezíveis e quais mereciam sua proteção e salvaguarda nos arquivos e, inclusive, as honras de museu." ${ }^{20}$

Outro autor que localiza na década de 1980 o início desta 'aliança' entre arte e fotografia é André Rouillé. Para ele, "no decorrer das últimas décadas do século $[\mathrm{XX}]$, o que surpreende é a quantidade crescente de obras total ou parcialmente fotográficas nas galerias, nos museus e coleçóes. ${ }^{21} \mathrm{E}$ a razão encontra-se principalmente na resistência que o suporte fotográfico oferece, ao opor-se à 'desmaterialização da arte', assim como na transformação dos valores artísticos que repercutiam as mudanças no mundo.
18 Para citar alguma delas: On the Art of Fixing a Shadow: 150 Years of Photography, que reuniu 415 fotografias na National Gallery of Art, em Washington nos Estados Unidos; The Art of Photography: 1839 - 1989, na Royal Academy of Art em Londres, apresentando 462 fotografias. No ano seguinte, em 1990, ainda na esteira das celebraçóes, o MoMA realizou em Nova Iorque a exposição Photography until now, organizada por John Szarkowski, então Diretor do Departamento de Fotografia, e composta por 275 obras fotográficas.

19 FONTCUBERTA, Joan. A câmera de Pandora: a fotografia depois da fotografia, 2012, p. 175.

20 Ibidem, p. 175.

21 ROUILLÉ, André. A fotografia entre documento e arte contemporânea, 2009, p. 354. 
22 KRAUSS, Rosalind. Os espaços discursivos da fotografia. Arte \& Ensaios, 2006, p. 161.

23 Ibidem, p. 161.

24 Ibidem, p. 165.

25 BATCHEN, Geoffrey. Burning with desire: The conception of photography, 1997, p.5.
Sobre a entrada da fotografia nos museus, principalmente as de cunho histórico, Rosalind Krauss faz uma crítica importante:

Quando decidiram que o lugar da fotografia do século 19 era dentro dos museus, que a ela era possível aplicar os gêneros do discurso estético e que o modelo da história da arte muito bem lhe convinha, os especialistas contemporâneos da fotografia foram longe demais. ${ }^{22}$

Um dos conceitos principais que foi alargado para incluir a fotografia no discurso estético da arte e que incomoda a autora é o conceito de 'artista'. Krauss acredita que ser artista implica muito mais que a simples paternidade das obras, "ele sugere também que se deva passar por um certo número de etapas para ter o direito de reivindicar um lugar de autor." ${ }^{23}$ De certo modo, a autora parece assentar esta crítica na maneira 'simplista' em que a prática fotográfica pode ser enquadrada. Se é preciso dias para se concluir um quadro, uma fotografia pode ser criada em fraçóes de segundo. Mas sabemos que a fotografia não se restringe ao momento do disparo, pois há questóes anteriores e posteriores que influenciam na qualidade da imagem fotográfica.

Por fim, a queixa colocada por Krauss é mais ampla e se localiza no modo como a fotografia foi desconstruída para que pudesse se encaixar nas categorias clássicas da história da arte, como autor, obra e gênero:

\footnotetext{
Hoje, em todo lugar, tenta-se desmantelar o arquivo fotográfico, quer dizer, o conjunto das práticas, instituiçóes, relações das quais surgiu inicialmente a fotografia do século 19, para reconstruí-lo no quadro das categorias já constituídas pela arte e sua história. Não é difícil imaginar quais os motivos de semelhante operação, mas o que é mais difícil de entender é a indulgência para com o tipo de incoerência que isso produz. ${ }^{24}$
}

A partir deste panorama, e apesar dos êxitos e das objeçóes, a integração da fotografia pelos museus proporcionou o surgimento de discursos fotográficos próprios de cada instituição, que narram a história da fotografia a partir de suas escolhas, mais preocupadas, neste primeiro momento, na recuperação de objetos e processos antigos que remetem aos primórdios da fotografia. Criaram-se, assim, distintas 'histórias da fotografia', a partir dos seus usos identificados e dos fragmentos materiais recolhidos pelas diferentes coleçóes, que foram ganhando forma ao longo dos anos e hoje contêm uma parte de tudo o que já foi produzido por esta mídia. Neste sentido, Geoffrey Batchen acredita que a história da fotografia erigida é, "portanto, a história coletiva e multifacetada das mesmas instituiçôes e discursos." 25 
A partir do momento em que é assimilada a uma coleção, a fotografia passa a responder por uma nova posição, adquire um novo 'uso', inserida em um novo discurso. De certo modo, náo deveria mais ser questionada individualmente sobre suas relaçóes com o real e, sim, sobre suas afinidades com a nova realidade daquela posição assumida.

John Tagg, na introdução do livro The burden of representation, busca refletir justamente sobre o peso que a fotografia carrega enquanto representação da realidade. Para o autor, a fotografia não é uma emanação mágica, "mas um produto material de um aparelho material definido para trabalhar em contextos específicos, por forças específicas, para fins mais ou menos definidos." ${ }^{26}$

Assim, a fotografia, apesar de toda a subjetividade impregnada desde quando ainda é imagem latente, ou seja, quando ainda não foi registrada pelo aparato fotográfico, é objetivamente real porque implica definiçôes materiais, encontradas na técnica e em sua definição funcional, pois sempre é criada para alguma finalidade. Neste sentido, Tagg volta a defender que a fotografia vai muito além da subjetividade, a qual muitas leituras acabam por direcioná-la. Tanto seu caráter material quanto os sistemas das quais faz parte conectam estas imagens com a realidade:

Para isso, no entanto, não devemos buscar algo "mágico" na mídia, mas os processos conscientes e inconscientes, as práticas e as instituiçôes através das quais a fotografia pode incitar uma fantasia, assumir o significado e exercer um efeito. O que é real não é apenas o item material, mas também o sistema discursivo do qual a imagem que ele traz é parte. ${ }^{27}$

Alguns destes sistemas discursivos são justamente aqueles que proporcionaram a aproximação da fotografia com instituições colecionadoras: a história da fotografia e seu entendimento acadêmico. Para Tagg, a origem deste movimento se encontra quando a fotografia é vista sob o olhar moderno, principalmente nas atividades desenvolvidas desde a década de 1960 pelo MoMA, quando houve a possibilidade de evoluir de uma longa crítica sobre suas funções e aplicaçôes para uma definição da fotografia como mídia.
26 TAGG, John. The burden of representation - Essays on Photographies and Histories, 1995, p. 3.

27 Ibidem, p. 4. 
O olhar moderno sobre a fotografia, de certo modo, inaugurou a possibilidade de pensar a forma independente do conteúdo. Só a partir daí, quando a visualidade e referente tornam-se dimensóes distintas na fotografia, é que seu entendimento enquanto aparato técnico de registro se expande e adentra a esfera da alta cultura, representada pelas coleçôes e museus de arte.

Até o momento em que a fotografia servia apenas como instrumento científico, técnico e de documentação, ela estava relegada a uma categoria secundária de imagem, utilizada principalmente como meio ilustrativo ou comprobatório. Quando passa a ser um objeto importante nos discursos artísticos e históricos, a fotografia alcança um patamar cultural acima daquele em que se encontrava no começo do século XX e passa a ser protagonista em diversas áreas do conhecimento e essencial para entender os rumos da arte contemporânea.

Ao conjugar o lastro histórico com as características únicas de objeto artístico, a fotografia foi dotada de uma importância cultural relevante, que culminou com a sua valoração para o colecionismo.

Apesar de a fotografia restabelecer uma 'heterogeneidade no coração do museu', enquanto prática e objeto ela continua operando no campo da estética e se destacando pela sua autonomia dentro do museu. Outros valores que carrega consigo, como o histórico e o social, nunca se descolarão, pois estão na essência da imagem fotográfica, mas é primordialmente sua aparência, é o que dá a ver, que desponta no contexto museológico.

\footnotetext{
O antigo espaço plural da fotografia limitar-se-á doravante a um único e abrangente campo: o estético. Assim como, livres de suas antigas funções, as pinturas e esculturas ganharam uma nova autonomia ao ser arrancadas das igrejas e palácios da Europa e transferidas para os museus no final do século XVIII e início do XIX, a fotografia assume agora sua autonomia ao também adentrar o museu. ${ }^{29}$
}

O entendimento da fotografia no contexto museológico, antes desta virada no contexto das artes, estava ligado primordialmente à reprodução das obras, como Walter Benjamin (1936) e André Malraux (1947) já haviam explorado em seus conhecidos textos. Para o primeiro, a obra de arte sempre foi reprodutível e, a partir do uso da fotografia, ela foi aprimorada, poden- 
do, assim, "acentuar certos aspectos do original, acessíveis à objetiva, mas não acessíveis ao olhar humano" e ainda "pode colocar a cópia do original em situaçóes inatingíveis para o próprio original. Ela pode, pincipalmente, aproximar o receptor da obra." ${ }^{30}$ Mesmo considerando estas vantagens surgidas com a aproximação da fotografia ao campo das artes, o autor insistiu, ao longo de sua análise, na perda da 'aura' das obras de arte a partir de sua reprodução. "Mesmo que essas novas circunstâncias deixem intacta a continuidade da obra de arte, elas desvalorizam, de qualquer modo, o seu aqui e agora." ${ }^{31}$ Claro que este posicionamento está impregnado pelo contexto histórico no qual o autor estava inserido, quando a fotografia ainda engatinhava.

Identificamos nesta reflexão de Benjamin que a perda da aura deve-se principalmente à irreparável possibilidade de reprodução mecânica da obra de arte, porém, esta mesma aura seria recuperada por meio da própria fotografia, que possibilita sua reprodução e a consequente disseminação de sua existência.

Ao antever que a fotografia estaria no cerne da arte contemporânea, seja como ferramenta criativa ou pela possibilidade de reprodução e divulgação de obras, possibilitando, assim, se tornarem mais próximas do espectador, Benjamin antecipa de certo modo algumas premissas do Museu Imaginário de André Malraux.

Para o escritor francês, a fotografia seria o meio primordial para a criação de um museu sem paredes, constituído a partir de reproduçôes de obras relevantes da história da arte. Sem desprezar a obra original, a fotografia opera na esfera do conhecimento ao permitir o acesso a objetos distantes do espectador. Assim, a reprodução "muitas vezes substitui a obra-prima tradicional pela obra significativa, o prazer de admirar pelo de conhecer." 32

Ainda sobre o papel da fotografia enquanto método de reprodução, para Malraux, ele não rivaliza com a obra-prima, mas a evoca e a sugere, é um modo de dinamizar a existência de obras que muitas vezes pertencem a coleçôes e arquivos inacessíveis ou estão situadas em lugares longínquos, "muitas destas fotos desempenharam o papel de embaixadores." 33

Podemos considerar que esta reflexão encontra seu ápice na contemporaneidade, pois hoje grandes coleções artísticas e históricas abrem-se e colocam em circulação reproduçôes fotográficas da quase totalidade do seu acervo, dispostas para consulta em seus sites institucionais, e as divulgam com apoio de redes sociais e outras ferramentas no ambiente digital. Evidente que as reproduçóes não transmitem a mesma sensação do contato direto com a obra, principalmente porque há a perda da escala e de detalhes que só podem ser detectados em contato direto com as obras, mas ainda assim é
30 BENJAMIN, Walter. Magia e técnica, arte e politica: ensaios sobre literatura e história da cultura, 2012, p. 182.

31 Ibidem, p. 182.

32 MALRAUX, André. O Museu Imaginário, 2015, p. 77.

33 Ibidem, p. 108. 
34 Ibidem, p. 108.

35 CRIMP, Douglas. Sobre as ruinas do museu, 2005, p. 50.

36 MELO, Alexandre. Sistema da Arte Contemporânea, 2012, p. 78. válida a observação de Malraux de que a reprodução "leva-nos a contemplar as obras-primas que nos são acessíveis, não a esquecê-las; e, sendo acessíveis, que conheceríamos nós, sem a reprodução?"34 Sem as cópias das obras o conhecimento fica limitado, só poderíamos descobrir o que estivesse fisicamente próximo de nós.

Crimp amplia este pensamento ao afirmar que a fotografia, além de um meio de acesso às obras de arte, funciona como um instrumento organizador ao permitir que as obras possam ser 'utilizadas' de outras maneiras, como em páginas de livros que podem estampar duas obras distintas uma ao lado da outra, ou ainda como objeto de projeção em palestras e, principalmente, como objeto de estudo.

\footnotetext{
Qualquer obra de arte passível de ser fotografada pode tomar assento no supermuseu de Malraux. Mas a fotografia não assegura somente que uma diversidade de objetos, fragmentos de objetos e detalhes de objetos tenha acesso ao museu; ao reduzir a heterogeneidade agora ainda mais ampla e uma única e perfeita similitude, ela assume o papel também de instrumento organizador. ${ }^{35}$
}

Assim, é possível considerar o museu imaginário como um embrião do que ainda está sendo construído, museus totalmente abertos para consultas através da internet, incluindo a possibilidade de visitar exposiçóes reproduzidas em ambiente virtual, tal e qual estão montadas no museu.

Alexandre Melo prega cautela antes de se tecer comentários favoráveis a esta 'passagem do museu imaginário para o museu virtual', que é sobretudo caracterizada por uma equivalência generalizada de imagens de todo o tipo que circulam no ambiente digital,

\footnotetext{
Devemos contudo ser cautelosos quanto a amplitude das transformaçôes que decorrem deste processo. Se a internet possibilita de facto uma democratização na produção e no acesso aos discursos sobre a arte contemporânea, não é claro que daqui decorra uma transformação quer nas hierarquias tradicionais, quer no sistema de consenso informal sobre os graus de reconhecimento e legitimação, que continua a ser prévio e determinante. ${ }^{36}$
}

Para o autor, esta aproximação e este acesso à arte possibilitados pela tecnologia digital não proporcionarão mudanças radicais nos processos relativos à legitimação e valoração das obras, como detalhado anteriormente. Esta dinâmica será sempre anterior e independente da divulgação das reproduçóes das obras de arte. O amplo conhecimento do que já é reconhecido 
como obra não tem influência no seu valor de mercado, mas sim no valor de culto.

Quando a fotografia passa, então, a ser vista como uma obra de arte, portanto, um objeto dentro do museu, ela tem seus dois 'usos' abraçados por estas instituiçóes. Antes como instrumento, depois como produto da cultura. Enquanto prática, ocupa-se principalmente da reprodução de obras, que continuará a ser uma fotografia, com características bem próximas do original, perdendo em alguns casos somente a informação na escala do trabalho reproduzido. Conforme notou Debray, "uma estátua impressa em papel deixa de ser realmente uma estátua, um quadro deixa de ser verdadeiramente um quadro, mas uma foto reproduzida continua sendo uma foto." 37

Apesar de tudo, a fotografia enquanto meio de reprodução continuará a ser protagonista, pois é ela que empresta a sua linguagem visual para que sejam desenvolvidos novos produtos que satisfaçam os olhares e o desejo de conhecimento dos espectadores contemporâneos. Se anteriormente a fotografia era a única visualidade possível para que determinadas obras de arte pudessem ser contempladas, graças à sua habilidade em reproduzir o real, hoje ela não se sustenta sozinha. É necessário que esteja em intensa relação com o ambiente digital e virtual para que possa ainda ser relevante neste contexto:

O que as novas tecnologias promovem é, em parte, a dissolução da própria integridade das imagens, que agora se tornam irrelevantes ou opcionais dentro do infinito banco de imagens. As imagens são, cada vez mais, fragmentos circunstanciais e transitórios de uma cultura que tende a marcar as suas representaçôes sobre o estigma do ruído e da impotência. A imagem fotográfica perde gradualmente a sua totalidade, já não se sustenta na sua autonomia. ${ }^{38}$

Mesmo que não seja mais necessário um suporte físico para que a fotografia exista, em se tratando de reproduçóes de obras de arte, é cada vez mais necessário a existência de um suporte digital que valorize estes dados e saiba colocar a imagem em lugares de destaque, contemplando todas as dimensões da fotografia. Neste sentido também é preciso se preocupar com a qualidade da reprodução, pois se ela é uma miniaturização da obra, que pelo menos preserve cores, padróes e, acima de tudo, as suas informaçóes técnicas para que possamos de algum modo restaurar o que foi perdido entre a obra e a sua cópia.

Outro ponto a ser destacado é a fragilidade da fotografia digital. Ao mesmo tempo em que sua produção e seu acesso se tornam mais fácil com
37 DEBRAY, Régis. Vida e morte da imagem, 1994, p. 267.

$38 \mathrm{MAH}$, Sérgio. A fotografia na era da sua obsolescência, 2012, p. 7. 
39 BATCHEN, Geoffrey. Each Wild Idea: Writing, Photography, History, 2002, p. 179.

40 CRIMP, Douglas. Sobre as ruinas do museu, 2005, p. 134. a sua desmaterialização, é preciso cuidado, pois se não dermos o devido tratamento podemos perdê-la táo rápido quanto a criamos. Um simples movimento e apagamos o arquivo digital de algum modo que ele pode nunca mais ser encontrado nas vastas memórias digitais táo necessárias para dar conta de tamanho fluxo atual de informação. Assim, Batchen sintetiza: "a 'fotografia' hoje é sobre a reprodução e consumo, fluxo e troca, manutenção e interrupção de dados." ${ }^{39}$

Se é inegável que as mudanças na fotografia alteraram suas relaçôes com a arte, com os museus, suas coleçóes e seu público, com o avanço da fotografia digital em consonância com as tecnologias da comunicação, a pretensa estabilidade alcançada entre estes domínios sofrem mais um abalo.

As possibilidades de reprodução das coleçôes através da fotografia se expandem na medida em que novas telas no ambiente digital surgem para divulgá-las. Novas plataformas são criadas para que a interação com as cópias das obras não sejam mais estáticas e planas como a fotografia se apresentava até pouco tempo atrás. Ferramentas para ampliação, através de fotografias de alta resolução, nos trazem informações plásticas que nunca foram possíveis nem mesmo quando observamos uma obra de arte pendurada na parede em exibição nos museus e galerias.

Em relação às obras de arte em suporte fotográfico, que entram para as coleçóes museológicas, cada vez mais híbridas, também desestabilizam as estruturas e os valores estabelecidos para este tipo específico de objeto. Os padróes oriundos das obras de arte tradicionais, que tornaram possíveis a entrada destas imagens nas coleçóes, já não dão conta da amplitude expressiva da fotografia, e o cenário se torna mais complexo.

Se ela não perdeu seu lugar privilegiado enquanto instrumento, pois ainda é a principal via de acesso para se conhecer o conteúdo de coleçôes espalhadas pelo mundo, enquanto obra de arte ela teve sua força diluída, pois já não é mais aquela fotografia pura, como as antigas cópias de autor que interessavam aos colecionadores.

A fotografia se coloca cada vez mais como um desafio no campo das artes, para os museus e os colecionadores, justamente por seu caráter múltiplo. E mesmo que as instituições se dediquem à fotografia enquanto objeto prioritário de coleção, sempre haverá alguma lacuna, pois talvez a fotografia nunca será amplamente domada dentro dos limites dos museus. Cada vez mais é preciso concordar com a afirmação de Douglas Crimp: "a fotografia sempre ultrapassará as instituiçôes de arte, sempre participará de práticas não artísticas, será sempre uma ameaça à insularidade do discurso de arte.”40 


\section{Referências}

BADGER, Gerry. Collecting Photography. London: Mitchell Beazley, 2003.

BATCHEN, Geoffrey. Burning with desire: The conception of photography. Cambridge: Massachusetts Institute of Technology, 1997.

Each Wild Idea: Writing, Photography, History. Cambridge: Massachusetts Institute of Technology, 2002.

BAUDELAIRE, Charles. Le public moderne et la photographie. Études photographiques. n. 6, mai 1999. Disponível em: http://etudesphotographiques.revues. org $/ 185$.

BENJAMIN, Walter. Magia e técnica, arte e política: ensaios sobre literatura e história da cultura. São Paulo: Brasiliense, 2012.

CHALLINE, Eléonore. Photography and Memory. Études photographiques. n. 25, mai 2010. Disponível em: http://journals.openedition.org/etudesphotographiques/3442.

COSTA, Helouise. Da fotografia como arte a arte como fotografia: a experiência do Museu de Arte Contemporânea da USP na década de 1970. Anais do Museu Paulista. V.16, nº2, 2008, p. 131-173.

CRIMP, Douglas. Sobre as ruinas do museu. São Paulo: Martins Fontes, 2005.

DEBRAY, Régis. Vida e morte da imagem: uma história do olhar no ocidente. Petrópolis: Vozes, 1994.

DERRIDA, Jacques. Mal de arquivo: uma impressão freudiana. Rio de Janeiro: Relume Dumará, 2001.

DUBOIS, Philippe. O ato fotográfico e outros ensaios. Campinas: Papirus, 1993.

ENTLER, Ronaldo. Retrato de uma face velada: Baudelaire e a fotografia. Revista FACOM, n.17, 2007, p. 4-14.

FONTCUBERTA, Joan. A câmera de Pandora: a fotografia depois da fotografia. São Paulo: Editora G. Gilli, 2012, p. 172-183.

. A fotografia na era da sua obsolescência. In: SARDO, Delfim. Fotografia: Modo de Usar. Lisboa: Documenta, 2012.

KRAUSS, Rosalind. Os espaços discursivos da fotografia. Arte \& Ensaios 13. UFRJ, 2006, p. 155-167. 
MAH, Sérgio. A fotografia na era da sua obsolescencia. In: SARDO, Delfim. Fotografia: Modo de Usar. Lisboa: Documenta, 2012, p. 26-36.

MALRAUX, André. O Museu Imaginário. Lisboa: Ediçóes 70, 2015.

MELO, Alexandre. Sistema da Arte Contemporânea. Lisboa: Documenta, 2012.

ROUILLÉ, André. A fotografia entre documento e arte contemporânea. São Paulo: SENAC, 2009.

TAGG, John. The burden of representation - Essays on Photographies and Histories. Minneapolis: University of Minnesota Press, 1995. 